\title{
Lethal paralytic shellfish poisoning from consumption of green mussel broth, Western Samar, Philippines, August 2013
}

\author{
Paola Katrina Ching, ${ }^{\text {ab }}$ Ruth Alma Ramos, ${ }^{\text {ab }}$ Vikki Carr de los Reyes, ${ }^{b}$ Ma Nemia Sucaldito ${ }^{b}$ and Enrique Tayag ${ }^{b}$ \\ Correspondence to Paola Katrina Ching (e-mail: paolaching@gmail.com).
}

Background: In July 2013, the Philippines' Event-Based Surveillance \& Response Unit received a paralytic shellfish poisoning (PSP) report from Tarangnan, Western Samar. A team from the Department of Health conducted an outbreak investigation to identify the implicated source and risk factors in coastal villages known for green mussel production and exportation.

Methods: A case was defined as a previously well individual from Tarangan, Western Samar who developed gastrointestinal symptoms and any motor and/or sensory symptoms after consumption of shellfish from 29 June to 4 July 2013 in the absence of any known cause. The team reviewed medical records, conducted active case finding and a case-control study. Relatives of cases who died were interviewed. Sera and urine specimens, green mussel and seawater samples were tested for saxitoxin levels using high performance liquid chromatography.

Results: Thirty-one cases and two deaths were identified. Consumption of $>1$ cup of green mussel broth was associated with being a case. Seawater sample was positive for Pyrodinium bahamense var. compressum and green mussel samples were positive for saxitoxin. Inspection revealed villagers practice open defecation and improper garbage disposal.

Conclusion: This PSP outbreak was caused by the consumption of the green mussel broth contaminated by saxitoxin. As a result of this outbreak, dinoflagellate and saxitoxin surveillance was established, and since the outbreak, there have been no harmful algal blooms event or PSP case reported since. A "Save Cambatutay Bay" movement, focusing on proper waste disposal practice and clean-up drives has been mobilized.

$\mathrm{H}$ armful algal blooms (HAB), commonly referred to as "red tides", can be caused by many microalgae such as the proliferation of Pyrodinium bahamense var. compressum (Pbc) dinoflagellate. $H A B$ is predominant in tropical regions including the Philippines, with $\mathrm{Pbc}$ dinoflagellate-producing saxitoxin causing paralytic shellfish poisoning (PSP). This neurotoxin is water-soluble, acid stable and relatively heat stable even in high temperature. ${ }^{1}$ Toxin levels of 120 to 180ug can produce moderate symptoms while levels of 400 to 1060 ug can cause human death. ${ }^{2}$ Within 5-30 minutes, perioral tingling and numbness extending to face and neck can occur. Uncoordination, respiratory difficulty and sensorium alteration are evident in severe cases. ${ }^{3}$ Death can occur 1-12 hours after ingestion. ${ }^{4}$ Gastrointestinal symptoms include vomiting, diarrhoea and abdominal cramps.
The Philippines has the highest number of PSP cases reported in Asia $^{5}$ with 2124 PSP cases and 120 deaths reported from 1983 to 2002 . Green mussels (Pernavirides) and other bivalves were implicated for most cases. The first PSP outbreak was reported in the Western Samar region in 1983, the same region as this outbreak. The health hazards and socioeconomic impact of this outbreak prompted the Philippine Government to create the Toxic Red Tide Monitoring Programme in 1984.

Eutrophication, or excessive enrichment of nutrients in the water, can stimulate algal blooms. Increased phosphorous and nitrogen from sewage and agricultural run-off are conducive for phytoplankton production. Many Filipinos residing in coastal areas are dependent on bodies of water for their income and survival.

\footnotetext{
Field Epidemiology Training Program, National Epidemiology Center, Department of Health, Sta Cruz, Manila, Philippines

Department of Health, Sta Cruz, Manila, Philippines.

Submitted: 15 January 2015; Published: 8 May 2015

doi: 10.5365/wpsar.2015.6.1.004
} 
Cambatutay Bay, which surrounds Bahay and Gallego coastal villages in Tarangnan, is the primary source of the community's livelihood. It is well known for its green mussel farms and products like mussel chips, crackers and cookies. Tarangnan comprises 41 villages with a population of 25703 .

In July 2013, the Event-Based Surveillance \& Response Unit of the National Epidemiology Center received a report of paralytic shellfish poisoning (PSP) with two deaths in Gallego village in Tarangnan, Western Samar. A team from the Department of Health was sent to conduct an outbreak investigation to identify the implicated source and to evaluate risk factors.

\section{METHODS}

\section{Epidemiological investigation}

A suspected case was defined as a previously well individual from Tarangan, Western Samar who developed gastrointestinal symptoms and any motor and/or sensory and gastrointestinal symptoms from 29 June to 4 July 2013 after consumption of shellfish in the absence of any known cause. A confirmed case had blood or urine positive for saxitoxin. The outbreak response team reviewed medical records of outpatients and admitted patients at the local health centre and district hospital. Active case finding of communities from the two villages with reported cases was conducted. Relatives of recently deceased community members were interviewed.

An unmatched case-control (1:3) study was conducted. Controls were well individuals randomly selected in the same or nearby households of the two villages. They were excluded if they reported any motor, sensory or gastrointestinal symptoms or tested positive for saxitoxin. We used a standardized questionnaire to collect data for cases and controls on demographics, symptoms (except for controls), hygiene practices and history of food consumption for the past three days. We used EPI Info version 3.5.4 software for statistical analysis and calculated odds ratios (OR) and confidence intervals. Significant risk factors from bivariate analysis were then tested in multivariate analysis.

\section{Laboratory investigation}

Twenty-five urine and 100 blood specimens from cases and controls were collected one week after onset of illness and were tested by the Marine Science Institute, University of the Philippines, Diliman, Quezon City for paralytic shellfish toxins (PSTs) by precolumn oxidation high performance liquid chromatography.

\section{Environmental investigation}

The team collected $500 \mathrm{ml}$ of seawater and 30-40 green mussel and oyster samples from three coastal areas - Cambatutay Bay, Bahay village and Gallego village. Green mussel samples were tested by the regional Bureau of Fisheries and Aquatic Resources using mouse bioassay. Marine Science Institute tested seawater and shellfish samples for saxitoxin and dinoflagellates using pre-chromatographic oxidation reversed phase high performance liquid chromatography equipped with fluorescence detection. ${ }^{10}$

Investigators observed sanitation and food consumption practices in the two villages with the highest attack rates. Residents of the coastal areas were asked if algal blooms had been observed.

\section{RESULTS}

\section{Case characteristics}

A total of 31 cases were identified. The incubation period ranged from 1 hour to 23 hours (median 11 hours) with the first date of occurrence on 29 June 2013 and a peak on 1 July 2013 (Figure 1).Twenty-eight cases (90\%) reported circumoral and extremity numbness, 20 (65\%) reported dizziness and 17 (55\%) light headedness. Eight cases (26\%) were hospitalized; two died (case fatality proportion $=6 \%$ ). There were 18 (58\%) male cases; ages ranged from 3 to 59 years (median $=26$ years). The most affected age groups were $21-30$ years and $51-60$ years $(23 \%$ each).

All cases reported consuming green mussels, either raw, boiled or steamed; the total quantity ranged from three to 50 (median $=15$ ). Consumption of less than one cup up to six cups of broth were reported.

The two deaths were males, aged 3 and 50 years, both from the same household. The older male died due to cardiorespiratory arrest 15 hours after onset of illness. He had eaten 50 green mussels, both raw and cooked. The child was pronounced dead on arrival 10 hours after 
Figure. 1. PSP cases by date and time of onset, Tarangnan, Western Samar, Philippines, June to July 2013 $(n=31)$

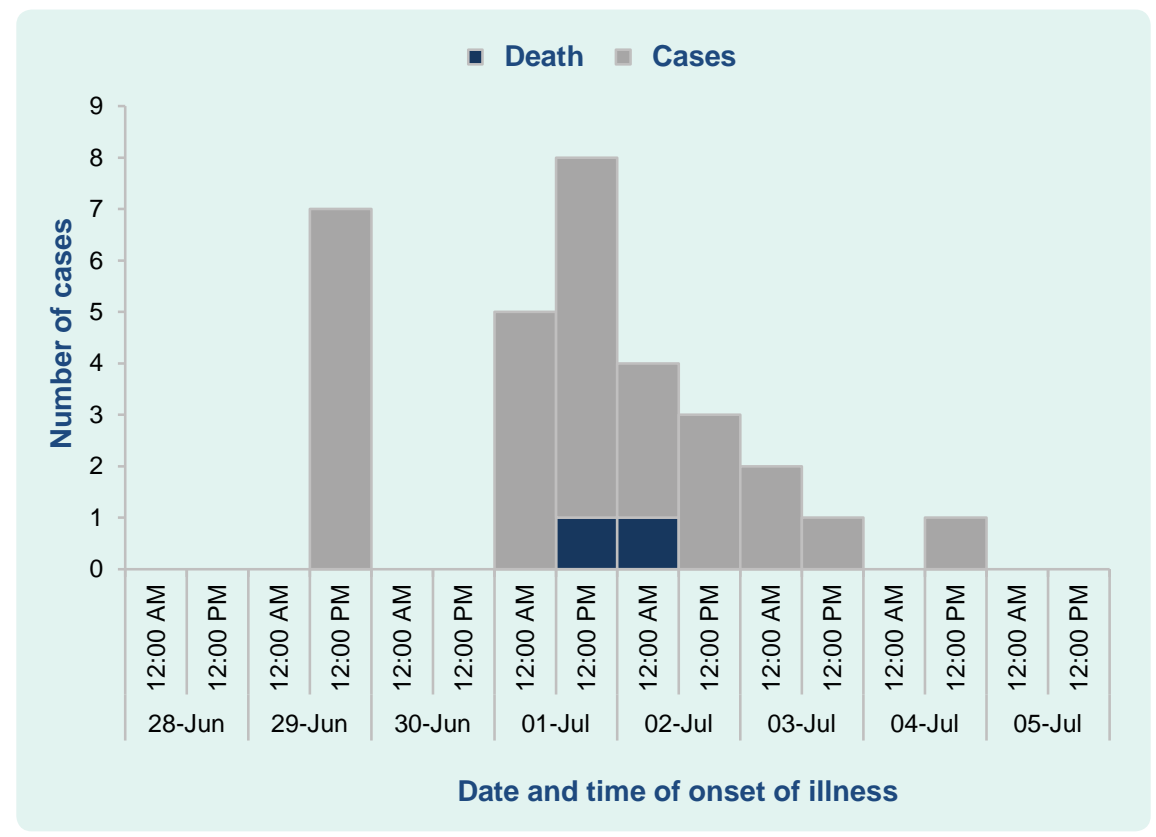

PSP, Paralytic shellfish poisoning.

illness onset. He had consumed more than two cups of mussel broth. Previous medical histories for both cases were unremarkable.

\section{Case-control study}

The case-control study comprised the 31 cases and 93 controls. Bivariate analysis revealed several significant risk factors: being male, harvesting their own food, eating raw foods, consuming at least one cup of mussel broth and consuming at least 15 green mussels. Interestingly, carbonated beverages were inversely associated with being a case (Table 1). However, only a small number of study participants (four cases and two controls) drank carbonated beverages. After multivariate analysis, consumption of at least one cup of green mussel broth emerged as the only significant association (OR: 12.0; 95\% confidence interval: 2.1-63.2).

\section{Laboratory examination}

Saxitoxins and $\mathrm{Pbc}$ dinoflagellates were detected in the three water samples. The green mussel and oysters specimens had PSTs at levels higher than the international regulatory limit. The 100 human serum and 25 urine samples were negative for PSTs.

\section{Environmental investigation}

We observed families practicing open defecation in the hills, river and coastal areas. There was no organized garbage collection system; garbage was dumped haphazardly in backyards and near coastal areas. The village captain reported that discoloration of the seawater surface was noticed by one of his constituents in early June.

We did not observe discoloration of surface waters in Cambatutay Bay during sample collection. However, seawater samples collected four metres below the surface had a reddish discoloration.

\section{DISCUSSION}

This PSP outbreak was caused by consumption of green mussels, specifically as a mussel broth, harvested in Cambatutay Bay in Tarangnan, Western Samar. High toxicity of saxitoxin was found in both green mussel and seawater samples and cases primarily presented with neurological symptoms consistent with other PSP outbreaks. ${ }^{6}$

Consuming at least one cup of broth was identified as a risk factor for illness. Saxitoxins are known to be 
Table 1. Factors associated with PSP, Tarangnan, Western Samar, Philippines, June to July 2013

\begin{tabular}{|c|c|c|c|c|}
\hline Characteristics & Case $n(\%)$ & Control $n(\%)$ & Crude OR $(95 \% \mathrm{Cl})$ & Adjusted OR $(95 \% \mathrm{Cl})$ \\
\hline \multicolumn{5}{|l|}{ Sex } \\
\hline Male & $18(58)$ & $33(36)$ & $2.5(1.1-5.7)$ & - \\
\hline Female & $13(42)$ & $59(64)$ & - & \\
\hline \multicolumn{5}{|c|}{ Consumption of mussel broth } \\
\hline 1 cup or more & $13(42)$ & $8(10)$ & $7.6(2.5-23.9)$ & $12.0(2.1-63.2)$ \\
\hline Less than 1 cup & $18(58)$ & $84(90)$ & - & \\
\hline \multicolumn{5}{|l|}{ Food source } \\
\hline Harvested & $18(58)$ & $24(26)$ & $3.9(1.6-10.2)$ & - \\
\hline Bought & $13(42)$ & $69(74)$ & & \\
\hline \multicolumn{5}{|c|}{ Type of foods eaten } \\
\hline Raw & $27(87)$ & $44(47)$ & $7.5(2.3-27.7)$ & - \\
\hline Cooked & $4(13)$ & $49(53)$ & - & \\
\hline \multicolumn{5}{|c|}{ Consumption of mussels } \\
\hline 1 mussel & $0(0)$ & $2(2)$ & $0(0-12.7)$ & - \\
\hline 2-4 mussels & $0(0)$ & $8(9)$ & $0(0-1.8)$ & \\
\hline 5-10 mussels & $1(3)$ & $13(14)$ & $0.2(0.01-1.6)$ & \\
\hline 11-14 mussels & $2(6)$ & $21(23)$ & $0.2(0.04-1.2)$ & \\
\hline 15 or more & $28(90)$ & $49(53)$ & $8.4(2.2-37.3)$ & \\
\hline \multicolumn{5}{|c|}{ Consumption of carbonated beverages } \\
\hline Yes & $4(0.1)$ & $2(0)$ & $0.1(0.0-0.9)$ & \\
\hline
\end{tabular}

OR, odds ratio; $\mathrm{Cl}$, confidence interval; PSP, paralytic shellfish poisoning.

heat stable in shellfish at a temperature of $100^{\circ} \mathrm{C}$ in household processing and therefore can dissipate from green mussels into boiling water and become concentrated in broths. ${ }^{7}$ In another outbreak, a butter clam broth was found to have high saxitoxin levels, ${ }^{8}$ further supporting that boiling shellfish in water cannot destroy the toxin.

Another observation from the environmental investigation was poor sanitation practices of the villagers. Open defecation and garbage disposal in the coastal areas may have contributed to water pollution. Dumping of raw sewage makes more nutrients available for dinoflagellates and can increase occurrence of $\mathrm{HAB}^{9}$

This study has some limitations. First, there was no green mussel left over from the implicated meals for testing. Second, while there were human serum specimens available for saxitoxin testing, delays in specimen collection and reagent availability may have limited testing yield as saxitoxins are only excreted in the urine eight hours after ingestion. ${ }^{10}$ Third, the team arrived a week after the outbreak which possibly hindered testing of active and symptomatic cases. However, we were able to identify the source of this outbreak from both epidemiological and environmental results.

As a response to the outbreak, we recommended to the local government of Tarangan the banning of harvesting shellfish in Cambatutay Bay. Cambatutay Bay was also added as a sentinel site for dinoflagellate and saxitoxin monitoring. A "Save Cambatutay Bay" movement was created and core group members were mobilized in the community. This campaign focused on proper waste disposal practices and clean-up drives. There have been no HAB events or PSP cases since the outbreak stopped.

\section{Conflicts of interest}

None declared. 


\section{Funding}

This foodborne outbreak investigation was funded by the Department of Health, Philippines.

\section{Acknowledgements}

We are grateful for the support of the Center for Health and Development-Eastern Visayas, Samar Provincial Health Office, the Local Government Unit of Tarangnan, Tarangnan Municipal Health Office and the residents during the field investigation. We are also thankful for Christopher Mendoza of the Marine Science Institute for the laboratory examinations.

\section{References}

1. Hughes JM, Merson MH. Current concepts fish and shellfish poisoning. The New England Journal of Medicine, 1976, 295: 1117-1120. doi:10.1056/NEJM197611112952006 pmid: 988478

2. Shellfish toxins in foods: a toxicological Review and risk assessment. Technical Report Series No. 14. Canberra, Australia New Zealand Food Authority, 2001 (http://www.food
standards.gov.au/publications/documents/TR14.pdf, accessed 20 April 2015).

3. Kao CY. Paralytic shellfish poisoning. In: Falconer IR (ed), Algal Toxins in Seafood and Drinking Water. London, Academic Press, 1993.

4. Rodriguez $D C$ et al. Lethal paralytic shellfish poisoning in Guatemala. The American Journal of Tropical Medicine and Hygiene, 1990, 42:267-271. pmid:2316796

5. Azanza RV, Taylor FJ. Are Pyrodinium blooms in the Southeast Asian region recurring and spreading? A view at the end of the millennium. Ambio, 2001, 30:356-364. pmid:11757284

6. Hurley $\mathrm{W}$ et al. Paralytic shellfish poisoning: a case series. The Western Journal of Emergency Medicine, 2014, 15:378-381. doi:10.5811/westjem.2014.4.16279 pmid:25035737

7. Alexander $\mathrm{J}$ et al. Marine biotoxins in shellfish-Saxitoxin group. EFSA Journal, 2009, 1019:1-76.

8. State of Alaska Epidemiology. Paralytic shellfish poisoning-Alaska Peninsula, Kodiak. Bulletin No. 10, July 3, 1990. Juneau, State of Alaska, 1990 (http://www.epi.hss.state.ak.us/bulletins/ docs/b1990_10.htm, accessed 24 April 2015).

9. Gessner BD, Middaugh JP. Paralytic shellfish poisoning in Alaska: a 20-year retrospective analysis. American Journal of Epidemiology, 1995, 141:766-770. pmid:7709919

10. García C et al. Human intoxication with paralytic shellfish toxins: clinical parameters and toxin analysis in plasma and urine. Biological Research, 2005, 38:197-205. doi:10.4067/S071697602005000200009 pmid:16238098 